\title{
PELAKSANAAN EKSEKUSI JAMINAN FIDUSIA DALAM HAL DEBITUR WANPRESTASI PADA KOPERASI SIMPAN PINJAM WISATA BALI
}

\author{
I Wayan Wahyu Wisnanta, I Nyoman Putu Budiartha, Ni Made Puspasutari Ujianti \\ Fakultas Hukum Universitas Warmadewa, Denpasar-Bali, Indonesia
}

\begin{abstract}
Abstrak
Koperasi sangat berperan positif dalam meningkatkan kesejahteraan masyarakat di Indonesia, agar masyarakat luas dapat meningkatkan kesejahteraan. Koperasi memiliki tugas yang sangat penting untuk memajukan taraf hidup semua anggota masyarakat. Dalam melakukan tugasnya koperasi juga merupakan suatu tempat keuangan yang punya tujuan dalam memberi pinjaman dan kebutuhan jasa uang lainnya. Kajian ini mengkaji tentang pelaksanaan eksekusi jaminan fidusia dan faktor-faktor yang menghambat pelaksanaan eksekusi jaminan fidusia dimaksud apabila debitur wanprestasi di Koperasi Wisata Bali. Penelitian ini dilakukan menggunakan penelitian hukum Empiris. Adapun sumber data penelitian ini adalah data primer adalah data yang diperoleh dari penelitian yang dilaksanakan langsung di lapangan dan dari orang koperasi. Hasil penelitian menunjukkan pelaksanaan eksekusi jaminan fidusia di Koperasi Simpan Pinjam Wisata Bali adalah sesuai dengan Standar Operasional Prosedur (SOP) yang dimiliki oleh Koperasi Simpan Pinjam Wisata Bali dan tidak bertentangan dengan peraturan-peraturan yang ada. Faktor- faktor yang menjadi penghambat eksekusi jaminan fidusia dalam hal debitur wanprestasi ialah jaminan tidak didaftarkan di lembaga fidusia karena biaya dan waktu. Oleh karena itu, dalam mengeluarkan kredit dengan jaminan fidusia Koperasi Wisata Bali mesti membuat akta otentik di hadapan notaris dan didaftarkan pada Kementerian Hukum dan HAM agar lebih menjamin kepastian hukum atas kelalaian dalam kewajiban merawat benda jaminan fidusia sebagai tanggung jawab debitur fidusia.
\end{abstract}

Kata Kunci: Eksekusi; Jaminan fidusia; Koperasi

\begin{abstract}
Cooperatives hold a very positive role in the improvement of people's welfare in Indonesia, so that the welfare of the wider community can be enhanced significantly. Cooperatives perform a crucial task to improve the standard of living of all members of society. In carrying out its duties, the cooperative also acts as a financial place that has the purpose of providing loans and other money service needs. This study examines the implementation of the fiduciary guarantee execution and the factors that hinder the implementation of the said fiduciary guarantee if the debtor defaults at the Bali Tourism Cooperative. This research was conducted using empirical legal research. The data source of this research is primary data, which is data obtained from research carried out directly in the field and from cooperatives. The results show that the implementation of fiduciary security at the Bali Tourism Savings and Loans Cooperative is in accordance with the Standard Operating Procedures (SOP) owned by the Bali Tourism Savings and Loan Cooperative and does not conflict with existing regulations. Factors hampering the execution of the fiduciary guarantees in the event of defaulting debtors are guarantees that they are not registered at a fiduciary institution due to cost and time. Therefore, in issuing credit with a fiduciary guarantee, the Bali Tourism Cooperative must make an authentic deed before a notary and be registered with the Ministry of Law and Human Rights in order to further ensure legal certainty for negligence in the obligation to treat fiduciary collateral as the responsibility of the fiduciary debtor.
\end{abstract}

Keywords: Execution; Fiduciary guarantee; Cooperative

\section{PENDAHULUAN}

Untuk mendukung kemajuan serta untuk pelaksanaan pembangunan, tempat keuangan seperti koperasi ini sudah mengalami peningkatan yang lumayan cepat sejalan dengan pertumbuhan pembangunan ekonomi dan berkembangnya kesejahteraan dan untuk membuat layanan aman, maju (Kansil \& Kansil, 1993: 75).

Koperasi mempunyai peranan untuk melakukan pembangunan nasional di Indonesia. Peranan koperasi adalah menaikan taraf hidup untuk anggota dan untuk rakyat. Untuk melaksanakan tugasnya 
maka koperasi membentuk salah satu tempat keuangan yang punya tujuan memberi pinjaman dan jasa lainnya. Koperasi adalah badan usaha yang berwujud badan hukum setelah akta pendiriannya disahkan dan disetujui oleh pemerintah, ini sudah ada di dalam peraturan Undang-Undang Nomor 25 Tahun 1992 tentang koperasi.

Koperasi merupakan salah satu organisasi dengan tujuan bersama yang terdiri atas perorangan yang di haruskan tidak mementingkan diri sendiri, dan mampu melakukan kewajiban sebagai anggota koperasi dan mendapatkan hasil yang lumayan di organisasi (Hendrojogi, 2012: 20). Dengan pandangan luas koperasi adalah tempat berkumpulnya orang yang berkumpul dengan tujuan untuk mencari memajukan taraf hidup mereka (Untung H., 2005: 3).

Kajian-kajian tentang fidusia telah dilakukan oleh Yulinengsih (2013) bahwa penyelesaian ketika ada nasabah yang ingkar janji dapat dilakukan dengan hanya memberi teguran saja dan negosiasi. Eaksekusi jaminan fidusia di Koperasi Simpan Pinjam Bali di Denpasar tidak didaftarkan tetapi melalui akta di bawah tangan saja (Jaya \& Priyanto, 2014). Kajian lain tentang eksekusi jaminan fidusia ialah yang dilakukan oleh Hutagalung (2013) dan Badriyah dkk. (2019). Namun kajian serupa belum dilakukan di Bali. Walaupun telah dilakukan tidak ada kepastian bahwa di Koperasi Simpan Pinjam Wisata Bali telah dilaksanakan akta otentik.

Dari latar belakang tersebut diatas, masalah yang dikaji dalam penelitian ini adalah: 1) Bagaimanakah Pelaksanaan Eksekusi Jaminan Fidusia dalam Hal Debitur Wanprestasi di Koperasi Wisata Bali? 2) Faktor-faktor apakah yang menjadi hambatan dalam Pelaksanaan Eksekusi Jaminan Fidusia dalam Hal Debitur Wanprestasi di Koperasi Wisata Bali?

Dalam karya ilmiah hakikatnya mempunyai suatu tujuan, baik dilihat dari segi teoretis maupun segi praktisnya. Tujuan penelitian ini ialah untuk memahami dan menemukan hal-hal yang berkaitan dengan pelaksanaan eksekusi benda jaminan Fidusia di Koperasi Wisata Bali dan untuk lebih memahami secara mendalam mengenai faktor-faktor yang menjadi kendala dalam pelaksanaan eksekusi jaminan di Koperasi Wisata Bali.

\section{METODE PENELITIAN}

Metode yang digunakan dalam penelitian ini adalah: metode hukum Empiris, metode Hukum tentang pemberlakuan atau penerapan kegunaan hukum yang ada peristiwa hukum tertentu dimasyarakat. Dengan menggunakan sumber data yang didapatkan di masyarakat untuk memperoleh data yang benar, dengan secara langsung meneliti di Koperasi Simpan Pinjam Wisata Bali, dengan menggunakan dua jenis data. Primer diperoleh melalui penelitian lapangan yang bersumber dari informan, yaitu pengurus dan anggota koperasi Simpan Pinjam Wisata Bali serta responden, dan data sekunder yaitu data yang diperoleh dari penelitian kepustakaan yang meliputi sumber hukum primer berupa peraturan perundang-undangan yaitu Kitab Undang-undang Hukum Perdata, Undang-undang Nomor 25 Tahun 1992 tentang koperasi, Undang- undang Nomor 42 Tahun 1999 tentang jaminan fidusia, PP Nomor 9 Tahun 1995 tentang Pelaksanaan Kegiatan Usaha Simpan Pinjam oleh Koperasi. Adapun Teknik pengumpulan data dalam penelitian ini yaitu data primer teknik pengumpulan datadata yang dilaksanakan melalui tanya jawab dengan pemilik dan para anggota. Dalam memperoleh data juga dengan melakukan pengamatan di koperasi. Teknik data sekunder, dengan cara mempelajari dokumen, dan mengumpulkan data yang benar dengan masalah tersebut, setelah itu dibaca dan dicermati, dan setelah itu dilakukan tindakan secara sistematis. Lokasi yang dipilih untuk mendapatkan data primer adalah di Koperasi Wisata Bali yang berkedudukan di Jalan Tohpati Denpasar yang beralamat di Jalan WR. Supratman 334 Tohpati-Kesiman Kertalangu, Kecamatan Denpasar Timur, Kota Denpasar Bali. Dalam hal ini peneliti menentukan sendiri responden dan informan mana yang sanggup mewakilkan penduduk, dengan meneliti di kantor. Dalam penelitian ini metode analisis yang digunakan adalah metode analisis kualitatif sesuai dengan permasalahan. Dimana setelah data terkumpul maka data tersebut diteliti dengan teori-teori yang relevan kemudian mendapatkan kesimpulan untuk menjawab masalah. 


\section{HASIL DAN PEMBAHASAN}

\section{Pelaksanaan Eksekusi Jaminan Fidusia dalam Hal Debitur Wanprestasi di Koperasi Wisata} Bali

Dalam usaha menjaga kesetabilan dan pemerataan ekonomi, koperasi ini telah memperlihatkan hasil pertumbuhan yang meningkat sejalan dengan pemerataan ekonomi di masyarakat dan peningkatan taraf hidup, juga menjamin kemajuan yang diinginkan banyak orang. Koperasi adalah badan usaha yang berbentuk badan hukum dinyatakan dalam penjelasan Undang-undang Nomor 25 Tahun 1992 tentang koperasi.

Berdasarkan Pasal 1 Ayat 1 Undang-undang Nomor 25 Tahun 1992 tentang Koperasi, Koperasi Indonesia adalah badan usaha yang beranggotakan orang-orang, seseorang, atau badan hukum koperasi dengan melandaskan kegiatannya berdasarkan prinsip koperasi, sekaligus sebagai gerakan ekonomi rakyat yang berdasarkan asas kekeluargaan.

Di Indonesia, lembaga fidusia lahir karena Arrest Hoggerechtshof 18 Agustus 1932. Lahirnya Arrest ini di karenakan terpengaruh asas konkordansi, juga dipengaruhi oleh keperluan yang mendadak dari pedagang kecil, pedagang besar, pedagang baru yang perlu kredit untuk mengembangkan usahanya. Perjalanan perundang-undangan fidusia sangat tidak cepat dikarenakan Undang- undang yang mengatur tentang jaminan fidusia baru ada pada tahun 1999, dikarenakan lahirnya era reformasi. Jaminan fidusia atau lengkapnya fiduciaire eigendomsoverdracht juga dibilang sebagai jaminan hak milik dengan cara kepercayaan, adalah wujud jaminan untuk benda bergerak disamping gadai yang dilakukan oleh yurisprudensi.

Jaminan fidusia adalah hak atas benda bergerak baik yang berwujud maupun tidak berwujud dan benda mati khususnya tidak dibebani hak tanggungan seperti yang di sebutkan dalam Undangundang nomor 4 Tahun 1996 tentang hak tanggungan yang berada dalam kuasa pemberi fidusia, sebagai agunan untuk menuntaskan hutang untuk memberikan hak yang utama pada penerima fidusia terhadap kreditur lainnya (Widjaya \& Yani, 2000: 54). Didaftarkannya objek jaminan fidusia pada kantor pendaftaran fidusia (KPF) setempat, maka kreditur atau penerima fidusia memperoleh hak prefensi.

Setiap perbuatan manusia dalam masyarakat selalu terkandung segala akibat yang akan terjadi. Akibat tersebut ada yang menguntungkan dan ada pula yang merugikan. Akibat yang menguntungkan sudah barang tentu tidak akan menimbulkan masalah, tetapi akibat yang merugikan tentunya akan menimbulkan masalah. Akibat yang merugikan tersebut merupakan suatu resiko. Begitu pula bila kita membuat suatu perjanjian maka kita tidak dapat lepas dari resiko yang terjadi, misalnya debitur pailit atau wanprestasi.

Dari hasil wawancara yang telah dilakukan dengan Bapak Ketut Sedia Yasa (Ketua Koperasi Simpan Pinjam Wisata Bali) dalam 3 tahun terakhir hanya sebagian kecil terjadi kredit macet seperti tabel dibawah ini:

Tabel 2.1 perbandingan kredit macet dan kredit lancar dari tahun 2016-2018

\begin{tabular}{|c|c|c|c|}
\hline Tahun & Jumlah nasabah & Kredit macet & Kredit lancar \\
\hline 2016 & 13 & 3 & 10 \\
\hline 2017 & 9 & 4 & 5 \\
\hline 2018 & 10 & 1 & 9 \\
\hline
\end{tabular}

Sumber: Ketua Koperasi Simpan Pinjam Wisata Bali

Yang menjadi anggunan dari kredit macet tesebut keseluruhannya menggunakan BPKB kendaraan bermotor telah dilakukan penyitaan seperti tabel dibawah ini:

Tabel 2.2 Penyitaan anggunan kredit macet dari tahun 2016-2018

\begin{tabular}{|c|c|c|c|}
\hline Tahun & Kredit Macet & $\begin{array}{c}\text { Jenis } \\
\text { anggunan }\end{array}$ & Keterangan \\
\hline 2016 & 3 & BPKB motor & Disita \\
\hline 2017 & 4 & BPKB motor & Disita \\
\hline 2018 & 1 & BPKB motor & Disita \\
\hline
\end{tabular}


Eksekusi jaminan fidusia diatur dalam Pasal 29 sampai dengan Pasal 34 Undang-undang Nomor 42 Tahun 1999 tentang jaminan fidusia. Eksekusi jaminan fidusia adalah penyitaan dan penjualan benda yang menjadi objek jaminan fidusia. Itu terjadi karena debitur cidera janji atau wanpretasi tepat pada waktunya, walaupun mereka telah di somasi (Sofwan, 1980: 67).

Pada awalnya Koperasi Simpan Pinjam Wisata Bali aktif pada tanggal 21 Maret 2012 sebagai salah satu koperasi yang ada di Banjar Tohpati. Pada awal pendiriannya, Koperasi Simpan Pinjam Wisata Bali didirikan oleh 35 orang antara lain adalah anggota dari Banjar Tohpati terletak di Jalan WR. Supratman 334 Tohpati Kesiman Kertalangu, Kecamatan Denpasar Timur, Kota Denpasar Bali. Sejak awal berdirinya Koperasi Simpan Pinjam Wisata Bali menempati kantor yang berada di Jalan WR. Supratman 334 Tohpati Denpasar.

Berdasarkan penjelasan Bapak Ketut Sedia Yasa (Ketua Koperasi Simpan Pinjam Wisata Bali) bahwa, proses pembentukan Koperasi Simpan Pinjam Wisata Bali ini termasuk agak rumit karena pada awal pendiriannya diawali oleh penolakan dari beberapa anggota Banjar Tohpati yang tidak setuju adanya Koperasi dilingkungan Banjar Tohpati karena biasanya pembentukan Koperasi dipicu iming-iming atau keinginan untuk memanfaatkan fasilitas atau agar dapat kecipratan rejeki, disetujuinya oleh Kadus Banjar Tohpati. Koperasi Simpan Pinjam Wisata Bali memulai modal awal koperasi sebesar Rp. 300.000.000,- (tiga ratus juta rupiah) dan saat ini modal koperasi telah menjadi sebesar Rp.500.000.000,- (lima ratus juta rupiah), serta jumlah anggota sebanyak 43 (empat puluh tiga) orang. Disamping itu Koperasi juga memiliki usaha yang meliputi usaha angkutan umum, cuci mobil. (Wawancara dengan bapak Sedia Yasa pada tanggal 02 Maret 2019).

Koperasi Simpan Pinjam Wisata Bali mempunyai beberapa mitra strategis, antara lain, IKSP (Induk Koperasi Simpan Pinjam) dalam hal likuiditas, dinas koperasi dalam hal pelatihan, informasi dan jaringan usaha, serta LKM lainnya untuk hubungan timbal balik dalam pelatihan, kerjasama dan jaringan usaha. Selain itu Koperasi Simpan Pinjam Wisata Bali juga mempunyai kerjasama dengan beberapa institusi keuangan untuk melakukan BI checking terhadap nasabah-nasabahnya. (Wawancara dengan Bapak Sedia Yasa pada tanggal 02 Maret 2019).

Mengenai jaminan, berdasarkan penjelasan Bapak Ketut Sedia Yasa (Ketua Koperasi Simpan Pinjam Wisata Bali) bahwa, di dalam pemberian pinjaman oleh Koperasi Simpan Pinjam Wisata Bali yang dapat dijadikan objek jaminan utang atau jaminan adalah benda tidak bergerak seperti tanah dan benda bergerak seperti motor dan mobil. Terkait dengan ruang lingkup Jaminan fidusia yang objeknya adalah benda bergerak dan tidak bergerak berupa bangunan yang tidak dapat dibebankan Hak Tanggungan, maka yang dapat dijadikan objek jaminan di Koperasi Simpan Pinjam Wisata Bali hanyalah benda bergerak berupa kendaraan bermotor seperti mobil dan sepeda motor. Tanah yang tanda buktinya masih berupa pipil, tidak dapat dipakai sebagai jaminan di dalam Koperasi Simpan Pinjam Wisata Bali (wawancara dengan Bapak Gede Ngurah Weda pada tanggal 02 Maret 2019).

Besarnya dana yang diserahkan untuk debitor dilihat dengan nilai jaminan. Jika terdapat jaminan yang bisa berpindah tempat seperti kendaraan bermotor, dilakukan dengan pembatasan usia pada mobil atau motor, di maksudkan untuk membatasi usia kendaraan tersebut maksimal 6 tahun dengan pinjaman paling mentok adalah 35\% dari penetapan harga paling rendah. Jika tanah di jadikan jaminan, berarti batasan yang sanggup diberi oleh Koperasi Simpan Pinjam Wisata Bali kepada nasabahnya yaitu taksiran harga terendah 55\%. Harga itu diperoleh dari pihak koperasi menilai secara ekonomi lebih dahulu dengan cara mengetahui nilai jual tanah tersebut dan pajaknya.

Eksekusi Jaminan yang dilakukan pada Koperasi Simpan Pinjam Wisata Bali sudah menurut peraturan perusahaan yang diawasi dalam standar operasional prosedur (SOP), proses eksekusi benda jaminan fidusia tersebut adalah sebagai berikut:

1. Apabila di layangkan surat teguran debitor melakukan wanprestasi pada tunggakan jatuh tempo pada 1 sampai 5 hari.

2. Bila tidak mengindahkan untuk membayar tunggakan tersebut maka diberi kesempatan 6 sampai 14 hari dari Koperasi Simpan Pinjam Wisata Bali.

3. Bila di hari ke 14 tidak ada tanggapan dari debitor maka akan dikeluarkan surat peringatan pertama oleh Koperasi Simpan Pinjam Wisata Bali.

4. Bila selama masa tenggang 15 hari tidak ada tanggapan dari debitor jadi Koperasi Simpan Pinjam Wisata Bali mengirimkan surat lainya yang berisi peringatan ke 2 rentan waktu dari 16 sampai 21 hari. 
5. Bila sudah dikirimkan tidak juga diindahkan maka debitor akan di berikan kesempatan oleh Koperasi Simpan Pinjam Wisata Bali dengan masa 22 hari sampai dengan 28 hari.

6. Bila sudah di berikan kesempatan dan tetap debitor tidak mengiindahkan untuk membayar, pegawai dari Koperasi Simpan Pinjam Wisata Bali untuk hal ini disebut debt collector akan melakukan system remedial.

7. Sesudah pihak Koperasi Simpan Pinjam Wisata Bali yaitu debt collector melakukan system remedial namun tetap tidak ada itikad baik dari pihak debitor maka dilakukan penarikan kembali barang tersebut dengan adanya (surat keputusan) SK dan lampiran suratsurat yang dikirimkan.

Lebih lanjut berdasarkan wawancara dengan Bapak Ketut Sedia Yasa (Ketua Koperasi Wisata Bali) menjelaskan bahwa, akibat hukum yang wanprestasi ialah :

1. Benda yang dijadikan jaminan harus segera di eksekusi untuk menutupi hutang dari debitur;

2. Debitur harus membayar biaya perkara apabila kreditur melakukan tuntutan melalui proses pengadilan dimuka hakim. Hal ini apabila debitur wanprestasi, dimana debitur telah memberikan kerugian kepada koperasi sehingga koperasi melakukan tuntutan melalui pengadilan, dan jika debitur terbukti bersalah dan telah diputusankan oleh hakim bersalah, maka debitur sebagai pihak yang kalah dalam persidangan harus membayar biaya dalam perkara (wawancara Dengan Bapak Gede Ngurah Weda pada tanggal 10 Maret 2019).

Eksekusi dilakukan dengan membuat perjanjian yang terpisah dari perjanjian pokoknya, yaitu dengan cara pencantuman klausula dalam perjanjian pinjaman mengenai penyerahan jaminan secara kepercayaan, dan penguasaan tanda bukti kepemilikan objek jaminan.

\section{Faktor-faktor apakah yang menjadi hambatan dalam Pelaksanaan Eksekusi Jaminan Fidusia dalam Hal Debitur Wanprestasi di Koperasi Wisata Bali}

Faktor-faktor yang menyebabkan Koperasi Simpan Pinjam Wisata Bali tidak mendaftarkan jaminan dengan jaminan fidusia adalah karena adanya faktor ekonomi jaminan yang didaftarkan akan memerlukan biaya dan prosesnya memerlukan waktu dan faktor budaya yaitu dalam penyaluran kreditnya Koperasi Simpan Pinjam Wisata Bali mengedepankan sistem kekeluargaan. Debitur dikatakan wanprestasi apabila debitur tidak melaksanakan kewajibannya membayar angsuran pokok dan bunga pinjaman perbulannya, selama tiga kali maka Koperasi Simpan Pinjam Wisata Bali melakukan upaya sebagai berikut:

1. Pemberitahuan melalui telepon kepada debitur apabila pinjamannya tidak dibayar sesuai perjanjian atau melewati waktu pembayaran;

2. Memberikan surat peringatan (SP) I pada debitur apabila pinjaman yang dipinjamnya mengalami tunggakan selama tiga kali;

3. Memberikan surat peringatan (SP) II apabila (SP) I tidak ditanggapi oleh debitur; APabila surat peringatan (SP) II tidak ditanggapi maka, akan dilakukan pendekatan pengurus dan badan pengawas. Koperasi Simpan Pinjam Wisata Bali akan melakukan eksekusi terhadap objek jaminan, pengambil alihan mencari objek yang menjadi jaminan seperti benda yang bisa berpindah tempat seperti otomotif secara dibawah tangan, juga untuk melakukan lelang pada objek jaminan berdasarkan Surat Kuasa Menjual yang menjadi satu pada perjanjian pinjaman yang tidak boleh dihilangkan, dengan maksud menjual objek secara langsung. Jika berhasil menjual setelah dikurangi biaya untuk melakukan penjualan itu, mengunakan sisa hasil penjualannya untuk menutupi utang debitur kepada Koperasi Simpan Wisata Bali, dan apabila ada kelebihan hasil penjualan maka Koperasi Simpan Pinjam Wisata Bali wajib mengembalikannya kepada debitur. Hal itu telah sesuai dengan perjanjian pinjaman, yang telah disepakati antara kreditur dan debitur.

\section{SIMPULAN DAN SARAN}

\section{Simpulan}

Pelaksanaan eksekusi jaminan fidusia yang dilakukan oleh Koperasi Simpan Pinjam Wisata Bali telah sesuai dengan standar operasional prosedur (SOP) yang dimiliki oleh Koperasi Simpan Pinjam Wisata Bali dan tidak bertentangan dengan peraturan Perundang-undangan yang berlaku. Debitur 
tidak melaksanakan kewajibannya membayar angsuran pokok dan bunga pinjamannya ada disebabkan oleh banyak faktor yang menjadi penghambat dalam eksekusi jaminan fidusia dalam hal debitur wanprestasi di koperasi wisata bali di denpasar, bahwa jaminan fidusia yang tidak didaftarkan dipengaruhi oleh faktor ekonomi, faktor waktu, faktor budaya (kepercayaan), dan faktor kekeluargaan. Faktor-faktor tersebut yang berpengaruh tidak didaftarkannya jaminan fidusia oleh Koperasi Simpan Pinjam Wisata Bali di Denpasar.

\section{Saran}

Bagi para prinsipal atau yang berperkara, sebelum melakukan pertemuan mediasi sebaiknya lebih mengetahui aturan yang mengatur tentang Mediasi tersebut. Bagi para penegak hukum seperti Hakim hendaknya memberikan penjelasan yang lebih rinci mengenai Prosedur Mediasi tersebut karena dalam prakteknya masih banyak dapat ditemui kasus-kasus seperti pertemuan mediasi yang diwakilkan.

\section{DAFTAR PUSTAKA}

Badriyah, S. M., Suharto, R., Susilowati, E., Haidar, M., \& Allam, F. (2019). Execution of Fiducia Guarantee in Government Pawnshop Companies in Semarang City. International Journal of Recent Technology and Engineering, 8(4), 4196-4200.

Hendrojogi. (2012). Koperasi Asas-asas, Teori, dan Praktik. PT RajaGrafindo Persada.

Hutagalung, A. S. (2013). Execution of Fiduciary Guarantee Under Law No. 42 of 1999 on Fiduciary Guarantee (A Socio-Juridical Analysis to Anticipate Its Effectiveness). Indonesia Law Review, 3(3), 204-212.

Jaya, A. A. G. A. K., \& Priyanto, I. M. D. (2014). Implementasi Eksekusi Jaminan Fidusia dalam Hal Debitur Wanprestasi pada Koperasi Simpan Pinjam Wisata Bali di Denpasar. Kertha Semaya, 02(04), 1-14.

Kansil, C. S. T., \& Kansil, C. S. T. (1993). Hukum Perusahaan Indonesia. PT. Pradnya Paramita.

Sofwan, N. S. S. M. (1980). Hukum Jaminan di Indonesia Pokok-Pokok dan Jaminan Perorangan. Liberty.

Untung H., B. (2005). Hukum Koperasi dan Peran Notaris Indonesia. ANDI.

Widjaya, G., \& Yani, A. (2000). Jaminan Fidusia: Seri Hukum Bisnis. PT. Raja Grafindo Persada, Jakarta.

Yulinengsih, S. (2013). Penyelesaian Wanprestasi dalam Perjanjian Kredit dengan Jaminan Fidusia pada Koperasi Jasa Keuangan Syari'ah Mandiri Sejahtera di Teluk Belitung. Universitas Islam Negeri Sultan Syarif Kasim Riau Pekanbaru. 